\title{
A Method of Measuring Wood Failure Percentage of Wood Specimens Bonded with Melamine-Urea-Formaldehyde Resins Using Image Analysis ${ }^{1}$
}

\author{
Minseok $\mathrm{KIM}^{2} \cdot$ Byung-Dae PARK (D) ${ }^{2, \dagger}$
}

\begin{abstract}
Transparent and colorless melamine-urea-formaldehyde (MUF) resins make it difficult to identify the area of wood failure percentage (WFP) in the fracture surface of bonded wood specimens. Therefore, in this study, we develop a method of measuring WFP after the adhesion strength measurement of MUF resins under shear stress. The fractured wood surface of block shear strength (BSS) specimens bonded with cold-setting MUF resins at three melamine contents $(20 \%, 30 \%$, and $40 \%)$ was marked black, and then, WFP was accurately measured via image analysis. WFP values measured using this method consistently increased with BSS as the melamine content increased, showing the reliability of this new method. The results suggested that this new method is useful and reliable for measuring the WFP of the fracture surface of wood specimens bonded with colorless adhesives such as urea-formaldehyde, MUF, and melamine-formaldehyde resins.
\end{abstract}

Keywords: block shear strength, image analysis, MUF resins, wood failure percentage

\section{INTRODUCTION}

Various shear strength tests are being used to measure an adequate adhesion strength of bonded-wood products (Hendrik et al., 2019; Park et al., 2020; Steiger et al., 2010). Cohesive failure (within bulk) and adhesion failure (at interphase) are important factors in wood bonding systems (Choi et al., 2020; Collett, 1972; Frihart and Hunt, 2010). In particular, the adhesion in interphase between wood and adhesives is important for bonded-wood products to have suitable adhesion performance (Marshall et al., 2010; Kamke and Lee, 2007). In other words, the resin that requires adequate adhesion performance must satisfy a certain level of the wood failure percentage (WFP). In general, WFP is one of the common adhesion performance evaluations, and used to determine the bond quality of wood-based composites. Therefore, the WFP is often used as a standard requirement of an adhesion performance of wood products such as plywood and glued-laminated timber (Glulam).

The WFP after adhesion strength tests is defined as the percentage of the fractured wood surface area to the total bonded area and is expressed as a percentage graded as 0 to $100 \%$ (Künniger, 2008). The WFP is one of the indicators of measuring the adhesion per-

\footnotetext{
${ }^{1}$ Date Received February 4, 2021, Date Accepted May 20, 2021

2 Department of Wood and Paper Science, Kyungpook National University, Daegu, 41566, Republic of Korea

$\dagger$ Corresponding author: Byung-Dae PARK (e-mail: byungdae@knu.ac.kr, ORCID: 0000-0002-9802-7855)
} 
A Method of Measuring Wood Failure Percentage of Wood Specimens Bonded with Melamine-Urea-Formaldehyde Resins Using Image Analysis

formance of wood adhesives used in the manufacture of wood products. For example, the WFP of phenol-formaldehyde (PF) resins was closely related to the adhesion performance of the resin as well as visual observation of the degree of penetration of the resin into the wood interphase (Paris and Kamke, 2014). In particular, the WFP of exterior grade adhesives such as resorcinol-formaldehyde (RF) resins, phenol-formaldehyde (PF) resins, phenol-resorcinol-formaldehyde (PRF) resins, or melamine-urea-formaldehyde (MUF) resins is an important requirement that must be satisfied by testing of bonded-wood products (Glavinić et al., 2020; Lim et al., 2020; Roh et al., 2018; Wen et al., 2020). Phenolic resins, including RF, PF, and PRF resins inherently show a dark and reddish-brown color of the bond-line, which makes it easy to identify the fracture area of wood in the bonded area (Cameron and Pizzi, 1985; Clauß et al., 2011; Frihart et al., 2004; Hse, 1972). The characteristic of these resins led to adopt the method of measuring their WFP using image-analysis. This method, which uses distinctive color contrast provided by wood and adhesive, is elaborate method of WFP measurement. This image analysis method is a relatively inexpensive and effective method, and manufacturers have continuously applied image-analysis to WFP measurement (Ellis, 1995; Zink and Kartunova, 1998). In fact, some works were already done for wood specimens bonded with phenolic resins, using image-analysis method (Lin et al., 2015; Gibson and Krahmer, 1980; Ginzel and Stegmann 1970; Yuan et al., 2012).

However, a transparent and color-less adhesives such as UF, MUF, or melamine-formaldehyde (MF) resins makes it difficult to determine the area of wood fracture surface in the bonded area after the shear test (Lubis et al., 2020; Künniger, 2008). MUF resins with low melamine content $(\sim 10 \%)$ are mainly used for interior grade wood products such as plywood, particle- board or medium density fiberboard (MDF) (Lubis et al., 2019). However, MUF resins with high melamine content $(\geq 20 \%)$ are used for manufacturing exterior grade plywood (Lubis et al., 2019), Glulam, or cross-laminated timber (CLT) because they are at low cost and have better resistance to water than UF resins (Dunky, 1998; Galih, 2020; Lim, 2020). In addition, cold-setting MUF resins with high melamine contents are also used for fabricating Glulam or CLT at room temperature (Baxter et al., 1973; Sauget et al., 2014; Frihart and Hunt, 2010; Lhelihe et al., 2016; Park et al., 2004).

Although MUF resins have been used for manufacturing various wood products (Künniger, 2008), this method has not been used for wood products bonded with colorless wood adhesives such as UF, MUF, or MF resins. In particular, a little study on the WFP measurement of cold-setting MUF resins has been conducted. Thus, this study was conducted to quantitatively determine the WFP of the block shear strength (BSS) samples bonded with cold-setting MUF resins, using image analysis method.

\section{MATERIALS and METHODS}

\subsection{Materials}

All MUF resins were synthesized using technical-grade melamine (99\%), urea granules (99\%), and formalin (37\%) purchased from Daejung Chemical, Korea. During the synthesis process, the $\mathrm{pH}$ was adjusted by adding aqueous solutions of acetic acid (20 wt \%) and $\mathrm{NaOH}(20 \mathrm{wt} \%)$. A mixture of carboxymethyl cellulose, CMC (95\%) and formic acid (85\%) was used as a hardener (Zhou et al., 2018). The lamina sample $(200 \times 25 \times 15 \mathrm{~mm})$ of Larch wood (Larix kaempferi Carr.) with $9 \sim 10 \%$ moisture content was used for the manufacture of all block shear samples. 


\subsection{Methods}

\subsubsection{Synthesis of cold-setting MUF resins}

Cold-setting MUF resins were synthesized by as reported in Jeong et al., 2019. Formalin was added to a reactor equipped with a mantle heater. The $\mathrm{pH}$ was adjusted to 8.5 by adding $\mathrm{NaOH}$ solution (20 wt\%). Simultaneously, melamine $(20,30$ or $40 \%$ solid content) was added to the reactor with continuous stirring at $40^{\circ} \mathrm{C}$. The temperature was then increased to $90^{\circ} \mathrm{C}$ and maintained for one hour. The first urea preparation was added to the reactor at an $\mathrm{F} /(\mathrm{M}+\mathrm{U})$ molar ratio of 1.7 and held for 10 minutes. At this time, the $\mathrm{pH}$ was adjusted to $7.5-8.0$ with $20 \mathrm{wt} \%$ acetic acid. The condensation reaction was maintained at $80^{\circ} \mathrm{C}$ until the target viscosity scale (J-K) of a bubble viscometer (VG-9100, Gardner Holdt, USA). At this time, the condensation reaction was stopped and the target water tolerance $(150 \%)$ was checked by the clouding point. The $\mathrm{pH}$ was adjusted to $7.5-8.0$ and the resins were cooled to $60{ }^{\circ} \mathrm{C}$. After cooling, the second urea preparation was added and maintained for 20 minutes to obtain the final molar ratio $(\mathrm{F} /(\mathrm{M}+\mathrm{U})=1.2)$. Once the reaction was completed, the MUF resins were cooled to ambient temperature and the $\mathrm{pH}$ was adjusted to $9.0^{-9.2}$.

\subsubsection{Hardener preparation}

Carboxymethyl cellulose (CMC) is dissolved in water and the solution is left to hydrate well for 24 hours. Afterwards, formic acid solution is added and then dissolved for 24 hours prior to use (Mansouri et al., 2009; Pizzi, 2003).

\subsubsection{Properties of cold-setting MUF resins}

The properties of cold-setting MUF resins such as non-volatile solid contents, viscosities, and water tolerance were evaluated. The viscosity was measured with a cone-plate viscometer (DV II +, Brookfield, NY, USA) operated at $25{ }^{\circ} \mathrm{C}$ and $60 \mathrm{rpm}$, using a spin- dle No. 2 for the cold-setting MUF resins. The non-volatile solids content of each sample was calculated by comparing the resin mass before and after drying the resins for 3 hours at $105{ }^{\circ} \mathrm{C}$ in oven. The water-tolerance value was determined by adding a certain amount of water into 1 gram resin sample in the tube, and checking the clouding point of the resin sample at $20^{\circ} \mathrm{C}$.

\subsubsection{Block-shear strength (BSS) test}

Prior to preparing the BSS samples of Larch wood, a 100 part of MUF resins were mixed with 15 part of the hardener based on the total mass of MUF resins (Choi, 2020). Fig. 1 shows a schematic diagram of the block shear specimens. And, Fig. 2 presents the process of BSS test using block shear specimens manufactured according to Fig. 1. The BSS samples were prepared by bonding two Larch wood laminae together with cold-setting MUF resins at a glue spread of 250 $\mathrm{g} / \mathrm{m}^{2}$ for both surfaces, and pressed for four hours under a pressure of $10 \mathrm{kgf} / \mathrm{cm}^{2}$ at ambient temperature.

Twenty BSS specimens (25 x $25 \times 15 \mathrm{~mm})$ were prepared by cutting the bonded laminae, and then tested under shear stress at a $1 \mathrm{~mm} / \mathrm{min}$ of the cross-head speed using an universal testing machine (H50KS, Hounsfield, Redhill, England) depending on the procedure of Korean standard (KS M 3705). The BSS val-
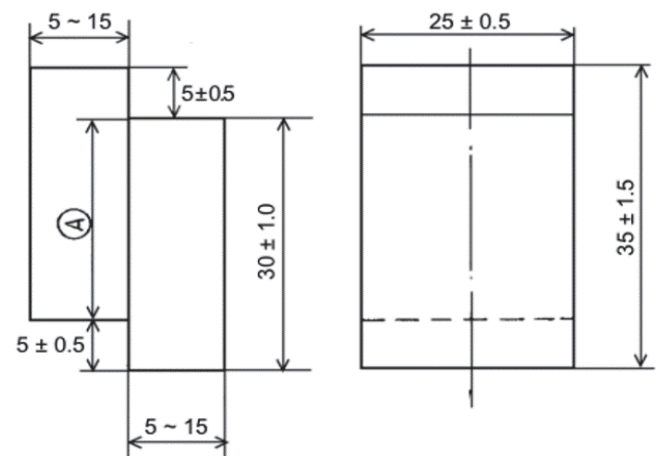

Fig. 1. Schematic diagram of block shear specimen (KS M 3705) (All scales are in $\mathrm{mm}$ ). 

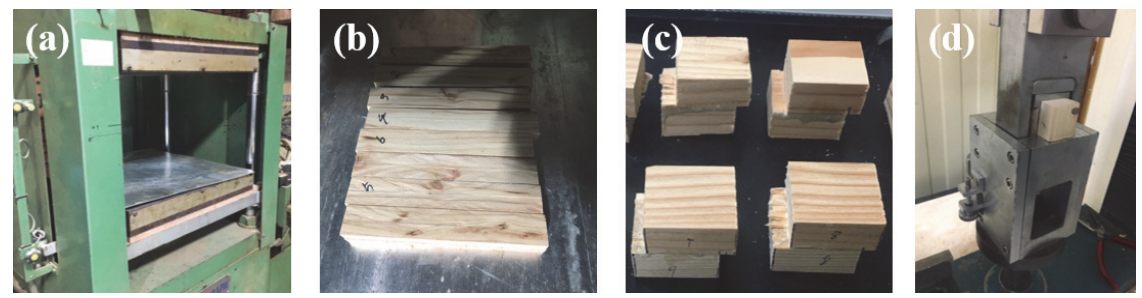

Fig. 2. Typical BSS test procedures. (a) Bonding laminae together using a press machine, (b) Bonded wood samples, (c) Block shear specimens, and (d) BSS test using universal testing machine.
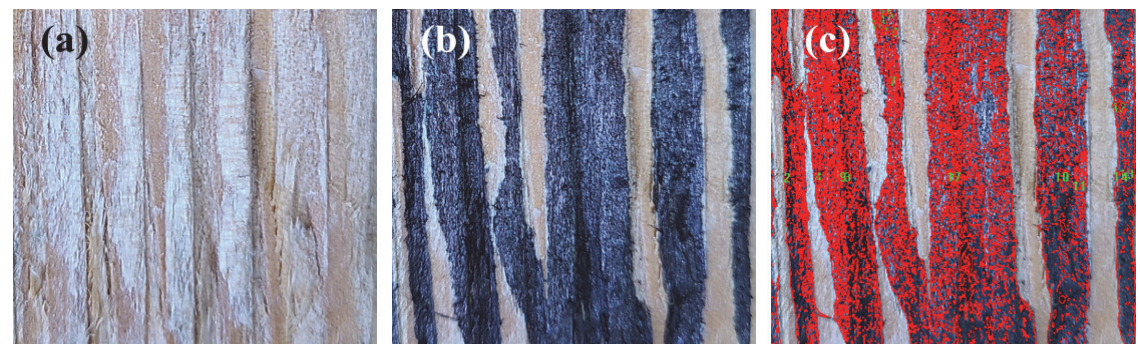

Fig. 3. Typical images for the WFP measurement of BSS test specimen bonded with cold-setting MUF resin using image-processing software. (a) Fractured surface after the test, (b) wood fractured surface marked as black color, and (c) fractured surface for image-processing.

ues in either dry or wet state were measured. Dry BSS value was obtained by testing 10 specimens at room temperature. By contrast, 10 specimens for wet BSS were treated for four-hour soaking in boiling water, twenty-hour drying in an oven, and then four-hour soaking in boiling water prior to testing them under shear stress. An average of the dry and wet BSS was determined by testing 10 specimens for each MUF resin at three levels of melamine content, respectively.

\subsubsection{WFP measurement}

The fractured specimens after the BSS test were collected for WFP measurement with a further processing. The wood fractured surface of specimens was closely inspected by naked eyes, and then the boundary of the wood fractured surface was specifically colored as black, using oil-borne black color pen for further process. Then, images of the fractured surface of a specimen were captured to obtain an average
WFP computed by image-processing software (IMT solution ver.22.5, Vancouver, British Columbia, Canada). Ten specimens for each dry and wet condition were tested for block-shear test, and the facture surface of these ten specimens were used to measure WFP using the image analysis. A minimum of three images per specimen was captured to obtain an average WFP of thirty samples for each.

Fig. 3 shows typical images of the fracture surface (Fig. 3(a)), wood fractured surface in black color (Fig. 3(b)), and processed images of wood fractured surface for the WFP measurement (Fig. 3(c)). As shown in Fig. 3 (a), it is difficult to identify the wood fractured area in the fracture surface due to transparent color of cold-setting MUF resins. To solve this problem, the wood fractured area was identified by naked eyes, and then marked as black color. As shown in the Fig. 3 (b), the wood fractured area is clearly identifiable after the black coloring. Then, images of the fracture sur- 
face were used for further processing with the image-analysis software (Fig. 3(c)). This software semiautomatically calculated the WFP by dividing the black-colored area with the total surface area.

\section{RESULTS and DISCUSSION}

\subsection{Properties of cold-setting MUF resins}

Table 1 presents the properties of cold-setting MUF resins with three melamine contents. The non-volatile solids content of MUF resins increased as the melamine content increased. The gelation time was also ac- celerated with an increase in the melamine content. This is reasonable because MUF resins with high melamine content generally have high condensation and molecular weight resins (Jeong and Park, 2019; Jeong et al., 2020; Tohmura et al., 2001). The water tolerance of both resins was maintained at about $150 \%$ as it was controlled in the synthesis. The viscosity of MUF resins increased as the melamine content increased.

\subsection{BSS and WFP}

Figs. 4 and 5 show typical images of the fracture surfaces of BSS specimens bonded with cold-setting

Table 1. Properties of cold-setting MUF resins at three levels of melamine content

\begin{tabular}{ccccccc}
\hline Resin type & $\begin{array}{c}\text { Melamine content } \\
(\%)\end{array}$ & $\mathrm{pH}$ & $\begin{array}{c}\text { Non-volatile solids } \\
\text { content (wt \%) }\end{array}$ & $\begin{array}{c}\text { Viscosity } \\
(\mathrm{mPa} . \mathrm{s})\end{array}$ & $\begin{array}{c}\text { Gelation time } \\
(\mathrm{s})\end{array}$ & $\begin{array}{c}\text { Water tolerance } \\
(\%)\end{array}$ \\
\hline \hline \multirow{3}{*}{ MUF resins } & 20 & 9.1 & 58.6 & 380 & 83 & 147 \\
& 30 & 9.1 & 63.2 & 412 & 73 & 158 \\
& 40 & 9.1 & 66.3 & 456 & 53 & 148 \\
\hline
\end{tabular}
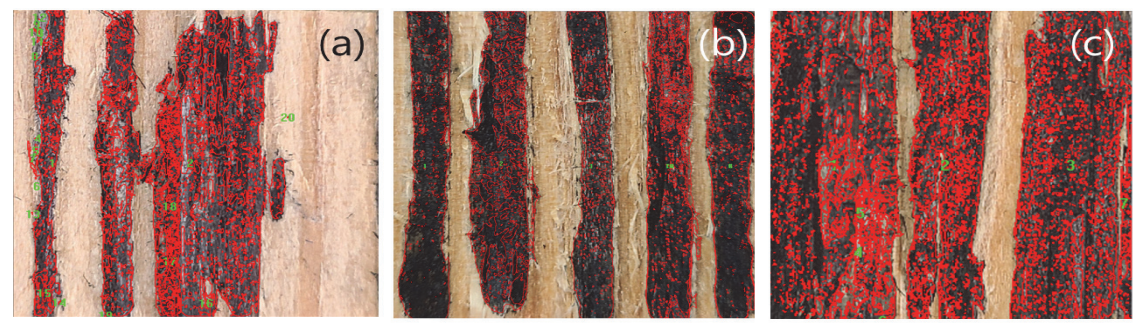

Fig. 4. Typical processed images for dry WFP of the BSS speciemen bonded with cold-setting MUF resins containing different melamine contents: (a) $20 \%$, (b) $30 \%$, and (c) $40 \%$.
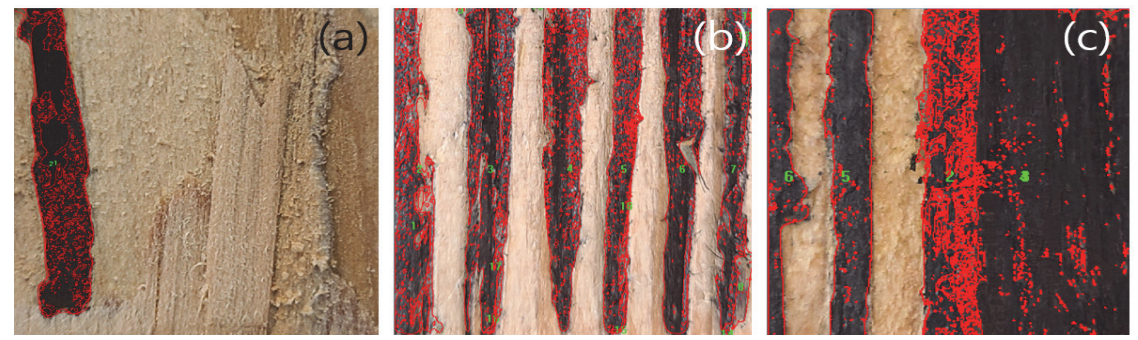

Fig. 5. Typical processed images for wet WFP of the BSS speciemen bonded with cold-setting MUF resins containing different melamine contents: (a) 20\%, (b) $30 \%$, and (c) $40 \%$. 
A Method of Measuring Wood Failure Percentage of Wood Specimens Bonded with Melamine-Urea-Formaldehyde Resins Using Image Analysis

MUF reins at three melamine contents for measuring the WFP after the BSS test in dry and wet state. As presented in Figs. 4 and 5, the wood fractured area of the specimens clearly increases as the melamine content increases for dry and wet state. The WFP of MUF resins at 20\% melamine shows the smallest area of wood fracture when compared with those at 30 and $40 \%$ melamine content.

This could be due to that the adhesion of cold-setting MUF resins was improved with an increase in the melamine content (Zanetti et al., 2002). In other words, the MUF resins that have penetrated into wood tissues in the interphase of bond-line will form a strong bond-line as the melamine content increased (Jeong et al., 2019; Aydin I, 2004; Kenai, 2011). In general, both melamine content and shear strength are related to WFP (Properzi et al., 2001). That is, high WFP values at the high melamine content resins indicate a strong adhesion of the resins.

Fig. 6 shows WFP and BSS of the cold-setting MUF resins at different melamine contents in dry and wet state. The results clearly showed that the WFP was closely related to the BSS as the melamine content increased. In the shear strength test, strong adhesion causes greater WFP. Therefore, it is necessary to see if the WFP measured by the method is related to the BSS. Obviously, WFP values in dry state were higher than in wet state for all levels of melamine content because the boiling process in hot water weakened the bond-line of the block-shear specimen, which affected the WFP results. And, cold-setting MUF resins containing $40 \%$ melamine content in both dry and wet state showed highest WFP values (dry: 97.5\%, wet: $88.4 \%$ ). This is consistent with the results showing the largest area of wood fracture at high melamine content (Figs. $4 \& 5$ ). These WFP values of the resins met the requirement level $(\geq 65 \%)$ of glulam in both dry and wet conditions specified by the Korean Standard (2015).

As expected by the WFP, the BSS increased with an increase in the melamine content of MUF resins. The MUF resins containing 40\% melamine also showed the highest BSS in dry and wet conditions. These results show that the BSS consistently increased as the WFP did. All dry BSS values were much higher than those in wet state, regardless of the melamine content. So, it is believed that increasing the melamine content results in high BSS and WFP by forming rigid bond-line between the resins and wood. In other words, the WFP of the cold-setting MUF resins measured by this image analysis method has a close correlation with BSS as a function of the melamine content. Therefore, this proposed method of measuring WFP seems to have a potential to be used for wood-based composite as well.
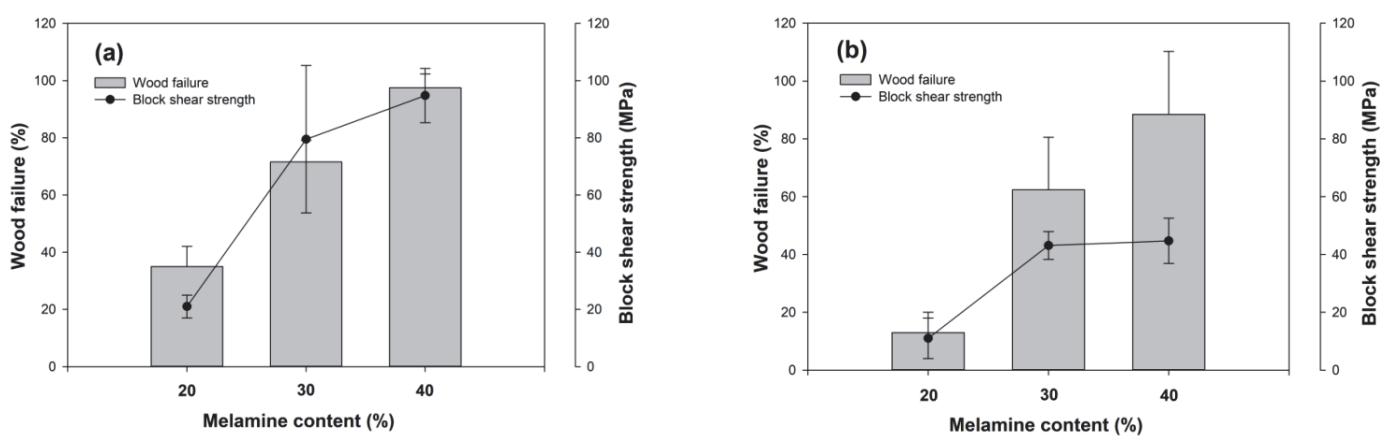

Fig. 6. WFP and BSS of the specimens bonded with cold-setting MUF resins at different melamine contents and testing conditions. (a) dry and (b) wet state. 


\section{CONCLUSION}

In this study, the method of measuring the WFP of the BSS specimens bonded with cold-setting and transparent MUF resins is presented. After the block shear test, the broken part (wood failure) was marked as black color to capture the images of fracture surface, and then these images were processed using an image analysis software for the accurate measurement of WFP. As expected, the WFP values measured by this method increased as the BSS increased in the dry and wet condition. It is thought that as the melamine content of the resin increases, a rigid bond-line is formed between the resin and substrates (wood), resulting in high shear strength and WFP. In other words, the proposed method of measuring the WFP is reliable, and will be worthwhile for industrial application. In addition, this method could be used to measure the WFP of not only MUF resin but also other transparent and color-less adhesives in future.

\section{ACKNOWLEDGMENT}

This work is supported by the Korea Forestry Promotion Institute (Grant No. 2019143D10-1921-AB01)

\section{REFERENCES}

Aydin, I. 2004. Activation of wood surfaces for glue bonds by mechanical pre-treatment and its effects on some properties of veneer surfaces and plywood panels. Applied Surface Science. 233(1-4): 268-274.

Baxter GE. Kreibich RE. 1973. A fast curing phenolic adhesive system. Forest Products Journal 23: 17-22.

Cameron, F.A. Pizzi, A. 1985. Effect of excessive pretreatment of pine timber with CCA wood preservatives on the bond quality of PRF and TRF wood adhesives. European Journal of Wood and Wood Products 43(4): 149-151.
Choi, G.W., Yang, S.M., Lee, H.J., Kim, J.H., Choi, K. H., Kang, S.G. 2020. A Study on the Block Shear Strength according to the Layer Composition of an $\mathrm{d}$ Adhesive Type of Ply-Lam CLT. Journal of the Ko rean Wood Science and Technology 48(6): 791-806.

Clauß, S., Joscak, M., Niemz, P. 2011. Thermal stability of glued wood joints measured by shear tests. European Journal of Wood and Wood Products. 69(1): 101-111.

Collett, B.M. 1972. A review of surface and interfacial adhesion in wood science and related fields. Wood Science and Technolgy. 6: 1-42.

Dunky, M. 1998. Urea-formaldehyde (UF) adhesive resins for wood. International Journal of Adhesion and Adhesives 18(2): 95-107.

Ellis, S. 1995. Correlation of waferboard internal bond and wood failure as measured by image analysis. Wood and Fiber Science 27(1): 79-83.

Frihart, C.R., Brandon, R., Ibach, R. 2004. Selectivity of Bonding for Modified Wood. The Adhesion Society 7: 329-332.

Frihart, C.R., Hunt, C.G. 2010. Adhesives with wood materials-bond formation and performance. Wood Handbook. 1: 10.1-10.24. General Technical Report FPL-GTR-190 Chapter 10.

Galih, N.M.G., Yang, S.M., Yu, S.M., Kang, S.G. 2020. Study on the Mechanical Properties of Tropical Hybrid Cross Laminated Timber Using Bamboo Laminated Board as Core Layer. Journal of the Korean Wood Science and Technology 48(2): 245-252. Glavinić, I.U., Boko, I., Torić, N., Vranković, J.L. 2020. Application of hardwood for glued laminated timber in Europe. Journal of the Croation Association of Civil Enginners 72(7): 607-616.

Hendrik, J., Hadi, Y.S., Massijaya, M.Y., Santoso, A., Pizzi, A. 2019, Properties of Glued Laminated Timber Made from Fast-growing Species with Mangium Tannin and Phenol Resorcinol Formaldehyde Adhesives. Journal of the Korean 
A Method of Measuring Wood Failure Percentage of Wood Specimens Bonded with Melamine-Urea-Formaldehyde Resins Using Image Analysis

Wood Science and Technology 47(3): 253-264. Hong, M.K., Park, B.D. 2017. Performance of MelamineUrea-Formaldehyde Resin Adhesives at Various Melamine Contents for Bonding Glued Laminated Timber under High Frequency Heating. Journal of the Korean Wood Science and Technology 45(4): 409-18.

Hse, C.Y. 1972. Wettability of southern pine veneer by phenol formaldehyde wood adhesives. Forest Products Journal 22(1): 51-56.

Jeong, B., Park, B.D. 2019. Performance of UreaFormaldehyde Resins Synthesized at Two Different Low Molar Ratios with Different Numbers of Urea Addition, Journal of the Korean Wood Science and Technology 47(2): 221-228.

Jeong, B., Park, B.D., Causin, V. 2019. Influence of synthesis method and melamine content of ureamelamine-formaldehyde resins to their features in cohesion, interphase, and adhesion performance. Journal of Industrial and Engineering Chemistry 79: 87-96.

Jeong, B., Park, B.D., Causin, V. 2020. Effects of Storage Time on Molecular Weights and Properties of Melamine-Urea-Formaldehyde Resins. Journal of the Korean Wood Science and Technology 48(3): 291-302.

Kamke, F.A., Lee, J.N. 2007. Adhesive penetration in wood - A review. Wood and Fiber Science 39(2): 205-220.

Kenai, S. 2011. Effect of curing time on shear strength of cohesive soils stabilized with combination of lime and natural pozzolana. International Journal of Civil Engineering 9(2): 90-96

Künniger, T. 2008. A semi-automatic method to determine the wood failure percentage on shear test specimens. European Journal of Wood and Wood Products 66(3): 229-232.

KS F 3021. 2018. Structural glued laminated timber. Korean Standards Association, 1-33
KS M 3705. 2015. General Testing Methods for Adhesives. Korean Standards Association, 1-32

Lhelihe, K. 2016. Cold-setting MUF resins adhesive prepared with concentrated fomaldehyde. Journal of Zhejian A \& F University 33(2): 300-305.

Lim, H., Tripathi, S., Sachin, Li., Minghao. 2020. Rolling shear modulus and strength of cross-laminated timber treated with micronized copper azole type C (MCA-C). Construction and Building Materials 259: 120419.

Lim, H., Tripathi, S., Tang, J.D. 2020. Bonding performance of adhesive systems for cross-laminated timber treated with micronized copper azole type C (MCA-C). Construction and Building Materials 232(1): 117208.

Lin, L., He, S., Fu, F., Wang, X. 2015. Detection of wood failure by image processing method: influence of algorithm, adhesive and wood species. European Journal of Wood and Wood Products 73(4): 485-491.

Lubis, M.A.R., Park, B.D. 2020. Influence of initial molar ratios on the performance of low molar ratio urea-formaldehyde resin adhesives. Journal of the Korean Wood Science and Technology 48(2): 136153.

Lubis, M.A.R., Park, B.D., Lee, S.-M. 2019, Performance of Hybrid Adhesives of BlockedpMDI/Melamine-Urea-Formaldehyde Resins for the Surface Lamination on Plywood. Journal of the Korean Wood Science and Technology 47(2): 200-209. Lubis, M.A.R., Jeong, B., Park, B.D., Lee, S.-M., Kang, E.-C. 2019. Effect of Synthesis Method and Melamine Content of Melamine-Urea-Formaldehyde Resins on Bond-Line Features in Plywood. Journal of the Korean Wood Science and Technology 47(5): 579-586.

Mansouri, H.R., Pizzi, A., Fredon, E. 2009. Honeymoon fast-set adhesives for glulam and fingerjoints of higher natural materials content. European Journal 
of Wood and Wood Products 67(2): 207-210.

Marshall, S.J., Bayne, S.C., Baier, R., Tomsia, A.P., Marshall, G.W. 2010. A review of adhesion science. Dental Materilas 26(2): 11-16.

Paris, J.L., Kamke, F. 2014. Wood-Adhesive Bondline Analyses with Micro X-ray Computed Tomography. Wood Science and Materials Science PhD: 302. Park, H.-M., Gong, D.-M., Shin, M.-G., Byeon, H.-S. 2020. Bending Creep Properties of Cross-Laminated Wood Panels Made with Tropical Hardwood and Domestic Temperate Wood. Journal of the Korean Wood Science and Technology 48(5): 608-617. Park, J., Kim, K., Hong, S. 2004. The Bending Strength and Adhesive Properties of PRF and MUF Glulam. Journal of the Korea Furniture Society 15(2): 19-27. Pizzi, A. 2003. Melamine-Formaldehyde Adhesives. Taylor \& Francis Group 32: 1-28.

Properzi, M., Pizzi, A., Uzielli, L. 2001. Honeymoon MUF adhesives for exterior grade glulam. Holzforschung 59: 413-421.

Roh, J.K., Kim, Y.G. 2018. Bonding Properties and Resin Exudation Characteristics of Pitch Pine, Journal of Korean Wood Science and Technology 46(3): 213-220.

Sauget, A., Pizzi, A., Guillot, A., Godart, S., Apolit, R., Mezzina, M. 2014. Performance of MUF honeymoon adhesive for glulam. European Journal of Wood and Wood Products 72(5): 697-698.

Steiger, R., Gehri, E., Richter, K. 2010. Quality control of glulam: Shear testing of bondlines. Eur. J. European Journal of Wood and Wood Products 68(3): 243-256.

Tohmura, S.I., Inoue, A., Sahari, S.H. 2001. Influence of the melamine content in melamine-ureaformaldehyde resins on formaldehyde emission and cured resin structure. Journal of Wood Science 47(6): 451-457.

Wen, M.-Y., Zhu, J.-Z, Zhu, M., Sun, Y.-X., Park, H.-J., Shi, J. 2020, Research on Flame Retardant Formaldehyde-Free Plywood Glued by Aqueous Polymer Isocyanate Adhesive. Journal of the Korean Wood Science and Technology 48(5): 755-764.

Zanetti, M., Pizzi, A. 2001. Low addition of melamine salts for improved melamine-urea-formaldehyde adhesive water resistance. Journal of Applied Polymer Science 88: 287-292.

Zhou, J., Yue, K., Lu, W., Li, M., Chen, Z., Cheng, X., Liu, W., Jia, C., Tang, L. 2018. Effect of CMC formic acid solution on bonding performance of muf for interior grade glulam. Cellulose Chemistry and Technology 52: 239-245.

Zink, A.G., Kartunova, E. 1998. Wood failure in plywood shear samples measured with image analysis. Forest Products Journal 48(4): 69-74. 